\title{
Influence of the probiotic preparation "Plantarum" in the diets of pregnant animals on the growth and development of young animals
}

\author{
Irina Funk ${ }^{1}$, Nikolay Vladimirov ${ }^{2}$, Alexander Yashkin ${ }^{2 *}$, Lyudmila Pautova $^{2}$, and Vitaly Gorshkov ${ }^{2}$ \\ ${ }^{1}$ Federal Altai Scientific Centre for Agro-BioTechnologies, 35, Nauchny Gorodok, Barnaul, 656910, Russia \\ ${ }^{2}$ Altai State Agricultural University, 98, avenue Krasnoarmeyskiy, Barnaul, 656049, Russia
}

\begin{abstract}
The work aims to study the effect of different doses of the experimental probiotic preparation "Plantarum" when fed to pregnant animals on their reproductive qualities, as well as on the growth and development of young animals. To obtain young animals, four groups of goats were formed in the type of the Saanen breed, 20 heads each. In the first (control) group, the animals received a standard diet, in the diet of the animals of the second, third and fourth groups in the second half of pregnancy, the probiotic preparation "Plantarum" was additionally introduced, containing Lactobacillus Plantarum, Propiobacterium freudenreihii, in dosages from 0.4 to $0.8 \mathrm{ml} / \mathrm{kg}$ of body weight per day. From the offspring of the goats of the experimental groups, four groups of 12 goats were formed. The highest percentage of preservation (94\%) and the highest business output of kids per 100 queens $(150 \%)$ were observed in the fourth experimental group $(0.8 \mathrm{ml})$. The goats of the second, third and fourth groups exceeded the body weight of their contemporaries from the control group by $3 \%$, $6.3 \%$, and $8.8 \%$. The highest indices of the absolute increase in body weight by age periods were noted in the fourth group of goats. There were no significant differences in body build indices during the experiment between the goats of the control and experimental groups. Thus, the maximum positive effect was observed with the introduction of a probiotic preparation into the diet of pregnant goats at a dose of $0.8 \mathrm{ml} / \mathrm{kg}$ of body weight per day.
\end{abstract}

\section{Introduction}

Dairy goat breeding is a promising branch of animal husbandry. The possibility of using goat milk in gerodietic and baby food justifies the interest in it on the part of consumers [1].

An important aspect of intensively developing animal husbandry, where the main task is to obtain the maximum yield while maintaining the productive potential of the animal, is the cultivation of healthy young animals. A fully developed offspring provides a constant replenishment and renewal of the herd, which affects the economic performance of production [2].

To obtain viable offspring, much attention is paid to the physiological state of their mothers. To ensure the normal physiological and immune status of pregnant animals, biologically active and environmentally friendly preparations, in particular probiotics, have been widely used recently. Probiotics are widely used in the diets of farm animals and poultry [3].

The positive effect of probiotics is to optimize digestion due to better absorption of nutrients, as well as activation of the immune system, which affects the resistance of animals $[4,5]$. In sheep that received probiotic preparations 10 days before insemination and 10 days before lambing, protein metabolism improves, and hematopoiesis is increased [6]. The addition of a probiotic to the diet of the breed increases the intake and assimilation of nitrogen from feed, helps to increase the digestibility of fiber, and increases the bodyweight of growing kids [7].

The use of probiotic preparations based on Lactobacillus reuteri, Lactobacillus alimentariu, Bifidobacterium bifidum, Enterococcus faecium in feeding Saanen goats results in an increase in the mass fraction of fat in milk [8]. The introduction of probiotic preparations into the diet of Creole goats provides an increase in the concentration of oleic, linoleic, and linolenic fatty acids in animal milk [9]. The positive effect of probiotic preparations based on Saccharomyces cerevisiae, Bacillus subtilis and Enterococcus faecalis on the growth of milk productivity and the quality of milk of Saanen goats has been proven [10].

Currently, the effect of probiotic preparations on the body of lactating goats is being actively studied, however, studies on the effect of probiotics on the reproductive ability of queens, as well as the growth and development of young animals in Western Siberia, are still few. In this regard, the study of the effectiveness of the use of probiotic drugs in the diets of pregnant and young animals is of scientific and practical interest.

The purpose of this work is to study the effect of different doses of the experimental probiotic preparation "Plantarum" when feeding to pregnant animals on their reproductive qualities, as well as on the growth and development of young animals.

Corresponding author: alexander.yashkin@gmail.com 


\section{Experimental}

The studies were carried out in the conditions of Agricultural Enterprise "EcoFerma" LLC (Altai Territory, Russia). Goats of the Saanen breed type and the young animals (goats) obtained from them at the age from birth to three months were selected as the objects of research. To obtain young animals, four groups of goats, twenty heads in each, were formed, considering body weight and age. In the first (control) group, the animals received the basic diet, which included oats, meadow hay, oat straw, carrots, green mass of herbs, and table salt.

In the diet of animals of the second, third and fourth groups in the second half of pregnancy, in addition to the basic diet, the probiotic preparation "Plantarum" was introduced. The probiotic preparation is a proprietary development of the laboratory of the microbiology of milk and dairy products of the Federal Altai Scientific Center of Agro-BioTechnologies (Barnaul, Russia). The probiotic includes pure cultures of Lactobacillus plantarum, Propiobacterium freudenreihii from the Siberian collection of microorganisms [11].

The probiotic preparation was fed to the animals of the second group together with concentrated feed at the rate of $0.4 \mathrm{ml}$ per $1 \mathrm{~kg}$ of the animal's body weight per day. To female goats of the third and fourth groups, the drug was administered in doses of $0.6 \mathrm{ml} / \mathrm{kg}$ of body weight/day. and $0.8 \mathrm{ml} / \mathrm{kg}$ body weight/day, respectively. From the offspring of the experimental groups of goats, the research formed four groups of goats, 12 heads each.

The fertility of the queens and the safety of the young were determined by considering all the born and survived baby goats up to three months of age per 100 uterine mothers.

The growth and development of goats were studied by monthly individual weighing on a scale with an accuracy of $0.1 \mathrm{~kg}$ and by considering the absolute, relative, and average daily gain in body weight by age periods. The assessment of the conformation of the goats was carried out considering the measurements of the main body articles and with the calculation of the body build indices following standard and generally accepted methods.

The experimental data were processed by the methods of variation statistics; the data were considered statistically significant at $\mathrm{P} \mathbf{0} 0.05$.

\section{Results and discussion}

\subsection{Reproductive qualities of queens and safety of kids}

The influence of the probiotic preparation "Plantarum" on the indices of reproduction of animals and the safety of breed for the period from birth to three months is presented in Table 1.
Table 1. Reproductive ability of animals and safety of breed.

\begin{tabular}{|l|c|c|c|c|}
\hline \multirow{2}{*}{ Indicator } & \multicolumn{4}{|c|}{ Group (n = 20) } \\
\cline { 2 - 5 } & 1 & 2 & 3 & 4 \\
\hline $\begin{array}{l}\text { Number of inseminated } \\
\text { animals, heads }\end{array}$ & 20 & 20 & 20 & 20 \\
\hline $\begin{array}{l}\text { Number of animals which } \\
\text { gave birth, heads }\end{array}$ & 20 & 20 & 20 & 20 \\
\hline $\begin{array}{l}\text { Live goats were born, } \\
\text { heads }\end{array}$ & 32 & 32 & 31 & 32 \\
\hline including: & & & & \\
\hline \multicolumn{1}{|c|}{ single } & 8 & 8 & 9 & 8 \\
\hline twins & 24 & 24 & 22 & 24 \\
\hline $\begin{array}{l}\text { Abortions, } \\
\text { heads }\end{array}$ & - & - & - & - \\
\hline $\begin{array}{l}\text { Total received breed, } \\
\text { heads }\end{array}$ & 32 & 32 & 31 & 32 \\
\hline including: & 15 & 16 & 15 & 16 \\
\hline \multicolumn{1}{|c|}{ yeanling } & 17 & 16 & 16 & 16 \\
\hline doe kid & 160 & 160 & 155 & 160 \\
\hline Fertility, \% & 28 & 28 & 28 & 30 \\
\hline $\begin{array}{l}\text { Breed saved by three } \\
\text { months of age, heads }\end{array}$ & 87.5 & 87.5 & 90.5 & 93.8 \\
\hline Preservation, \% & 140 & 140 & 140 & 150 \\
\hline $\begin{array}{l}\text { Business output of breed } \\
\text { per 100 queens, \% }\end{array}$ & & & \\
\hline
\end{tabular}

The data in Table 1 show that no definite relationship was found between the fertility of goats in the type of Saanen breed and the introduction of the probiotic preparation "Plantarum" into their diet in the second half of the pregnancy rate. Fertility was $155 \%$ in the third group and $160 \%$ in the first, second, and fourth groups.

However, it should be noted that an increase in the dose of the probiotic preparation "Plantarum" in the diet of pregnant goats had a positive effect on the preservation of their breed. The highest percentage of preservation $-93.8 \%$ - was observed in the fourth experimental group. The safety of young animals of the third and fourth groups exceeded the safety of young animals of the first (control) group by $3.0 \%$ and $6.3 \%$, respectively. The highest business output of kids per 100 queens, which was $150 \%$, was also observed in the fourth group. This indicator in the first, second and third groups was $140 \%$, which is $10 \%$ lower than the business output in the fourth group.

\subsection{Growth and development of kids}

The growth and development of an animal are closely related to its constitution. By the usefulness of the development of young animals, one can judge the potential of their productive qualities [12].

Body weight during the growth and development of an animal is one of the key criteria in assessing its productivity. During the experiment, the intensity of the change in the body weight of the experimental kids was assessed. Body weight measurement data are presented in Table 2. 
Table 2. Dynamics of body weight of goats in terms of age, $\mathrm{kg}$ (mean \pm standard deviation).

\begin{tabular}{|c|c|c|c|c|}
\hline \multirow{2}{*}{ Age } & \multicolumn{4}{|c|}{ Group $(\mathrm{n}=12)$} \\
\cline { 2 - 5 } & 1 & 2 & 3 & 4 \\
\hline At birth & 3.1 & 3.1 & 3.1 & 3.2 \\
& \pm 0.27 & \pm 0.38 & \pm 0.24 & \pm 0.17 \\
\hline 1 month & 6.5 & 6.7 & 6.9 & 7.0 \\
& \pm 0.19 & \pm 0.20 & \pm 0.34 & \pm 0.23 \\
\hline 2 month & $11.1^{\mathrm{bc}}$ & $11.5^{\mathrm{ac}}$ & $11.8^{\mathrm{a}}$ & $12.1^{\mathrm{a}}$ \\
& \pm 0.11 & \pm 0.26 & \pm 0.19 & \pm 0.29 \\
\hline 3 month & $14.7^{\mathrm{BC}}$ & $15.2^{\mathrm{AC}}$ & $15.6^{\mathrm{A}}$ & $16.0^{\mathrm{A}}$ \\
& \pm 0.15 & \pm 0.37 & \pm 0.13 & \pm 0.19 \\
\hline
\end{tabular}

a-c Means within rows with different superscript letters are significantly different $(\mathrm{P} \leq 0.01)$.

A-C Means within rows with different superscript letters are significantly different $(\mathrm{P} \leq 0.001)$.

The analysis of the obtained results shows that at birth the goats of the control and experimental groups did not have statistically significant differences in body weight. Significant differences in groups were observed in subsequent age periods, where goats had the advantage, in the diet of their mothers the probiotic preparation "Plantarum" was introduced. So, in the first month, the goats of the second, third and fourth groups exceeded the body weight of their peers from the control group by $2.3 \%, 5.3 \%$, and $7.5 \%$, respectively, in the second month - by $3.2 \%$, $6.3 \%(\mathrm{~Pa} 0.01)$ and $8.7 \%(\mathrm{~Pa} 0.01)$ and in the third month by $3.0 \%, 6.3 \%(\mathrm{~Pa} 0.001)$ and $8.8 \%(\mathrm{~Pa} 0.001)$.

For a more detailed characterization of the growth rate of the young stock obtained, the absolute, average daily, and relative gains were calculated, the results of which are presented in Figures 1-3.

The highest indices of the absolute increase in body weight by age periods were noted in the fourth group, where there was an increase in this indicator relative to the control in the period from one to two months by $10.4 \%$ and from two to three months - by $9.2 \%$.

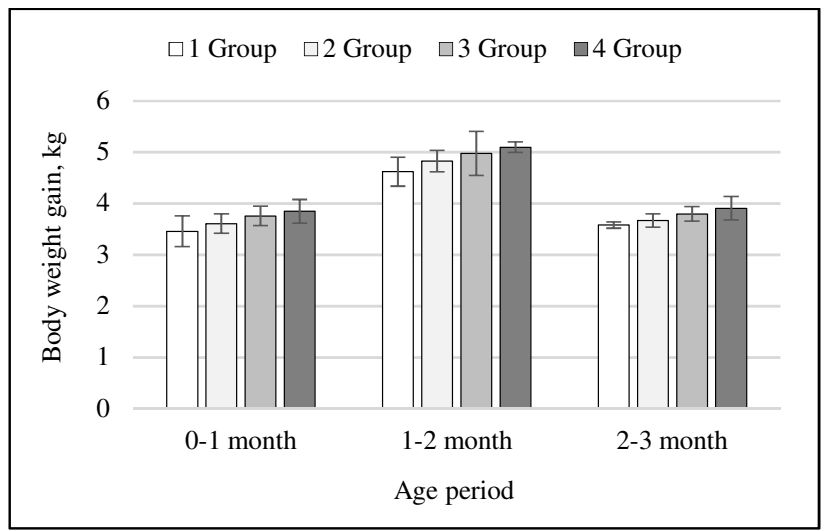

Fig. 1. Absolute gain in body weight of goats in terms of age by groups. Letters a, b, c, d show significant differences (Pa0.05) between the mean values.

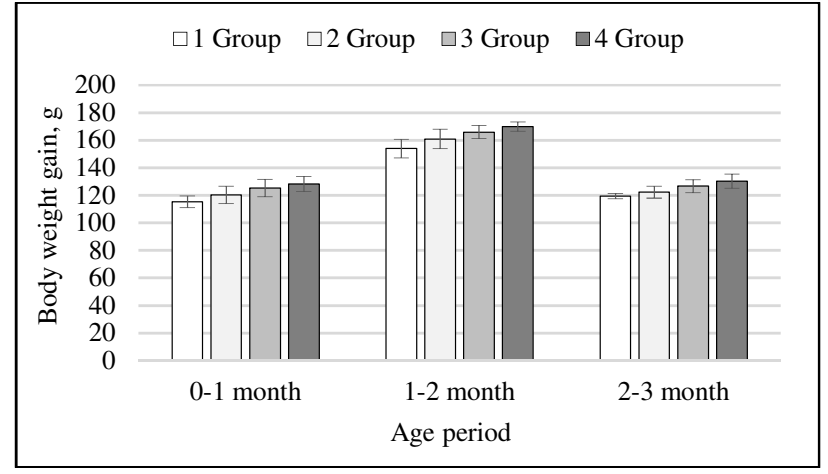

Fig. 2. Average daily gain in body weight of goats in the age aspect by groups. Letters a, b, c, d show significant differences (Pa0.05) between the mean values.

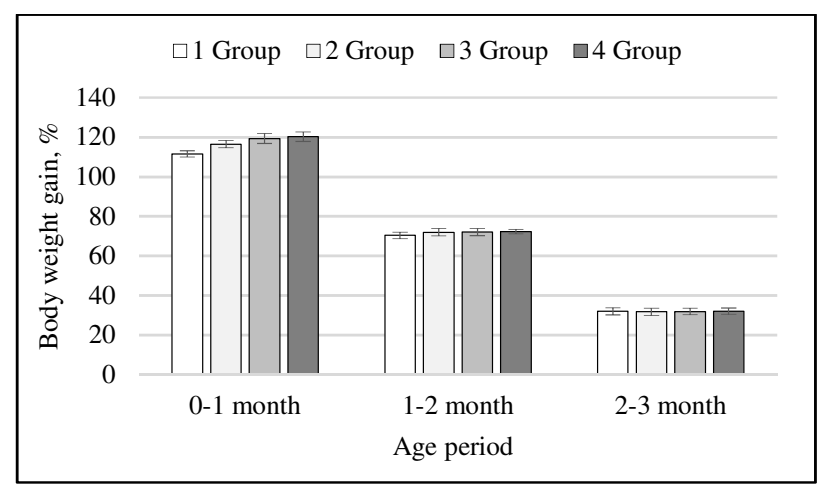

Fig. 3. The relative increase in body weight of goats in the age aspect by groups. Letters a, b, c, d show significant differences $(P \mathbf{p} 0.05)$ between the mean values.

The average daily gain in the mass of goats in the experimental groups in all recording periods exceeded the average daily gain in their contemporaries from the control group. The highest growth energy of animals of all experimental groups was noted in the period from the first to the second month of life, where the average daily gain in the second, third and fourth groups was 161, 166, and $170 \mathrm{~g}$, respectively, which is $4.55 \%$ higher than the control group (154 g), 7.79\% (Pa0.05) and 10.39\% (Pv0.05), respectively. Further, there was a gradual decrease in the intensity of growth and at the end of the third registration period (from two to three months), the average daily gain of animals of all groups ranged from 119.33 to $130.33 \mathrm{~g}$.

In terms of relative weight gain, the most intensive development of goats of all experimental groups was in the age period from birth to one month, where it was $111.6 \%$ in the first (control) group, $116.5 \%$ in the second group, $119.4 \%$ in the third group and $120.3 \%$ in the fourth group. In subsequent age periods, the research observed a regular decrease in the intensity of growth.

Proceeding from the foregoing, youngsters whose mothers' diets were introduced to various dosages of the experimental probiotic preparation "Plantarum" were characterized by higher growth energy concerning their peers from the control group. The highest growth rate was observed in goats whose mothers were fed probiotics at a dose of $0.8 \mathrm{ml} / \mathrm{kg}$ body weight/day, as evidenced by a significant increase in body weight of goats of the fourth group relative to the control by $8.8 \%$. The results obtained 
make it possible to judge the positive effect of the probiotic on the organism of experimental animals.

Our data are consistent with the results of studies by several authors. The use of a complex probiotic preparation (Lactobacillus acidophillus and Saccharomyces cerevisiae) in feeding breed provided an absolute increase in animal body weight of $8.03 \mathrm{~kg}$ with an average daily gain of $88 \mathrm{~g}$ against the background of an increase in feed conversion [13]. Similar data are given in [14], where Malabari kids that received a combined probiotic preparation (Saccharomyces cerevisiae, Saccharomyces boulardii, Lactobacillus acidophilus, Propionibacterium freudenreichii) had a maximum average daily weight gain (78 g) and the largest body weight (16 g) and the highest body weight. In [15], the superiority of the Jamunapari goat breed, which received an additive based on Saccharomyces cerevisiae, in body weight by $41.9 \%$ and the efficiency of feed conversion by $10.8 \%$ over the control animals.

\subsection{Exterior indicators of goats}

In addition to the growth rate of animals, the study of the exterior is important in assessing their health and productivity.

In our studies, the measurements of the main body articles of the goats of the experimental groups did not differ significantly from their peers from the control group. With age, the research observed a regular increase in the measurements of the physique of the experimental young animals.

The calculated physique indices make it possible to judge the harmonious development of experimental animals, which is characteristic of goats of the dairy direction of productivity (Figures 4-5).

There were no significant differences in body build indices during the experiment between the goats of the control and experimental groups. The indices of leg length and bone structure with age (by three months) decreased on average for groups by $3.1 \%$ and $28.8 \%$, respectively. In contrast, the indices of elongation, hip-chest, thoracic, and sagging increased with age: by $9.9 \%$ in the index of elongation, by $23.4 \%$ in the thoracic index, by $10.2 \%$ in the hip-thoracic, and by $13.4 \%$ in the index of sagging.

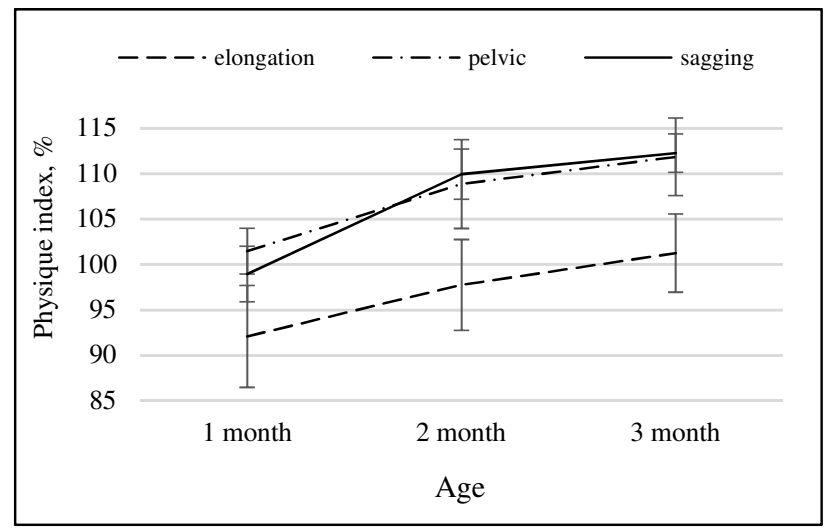

Fig. 4. Body build indices of goats according to the indices of elongation, pelvic and sagging (average values for all groups).

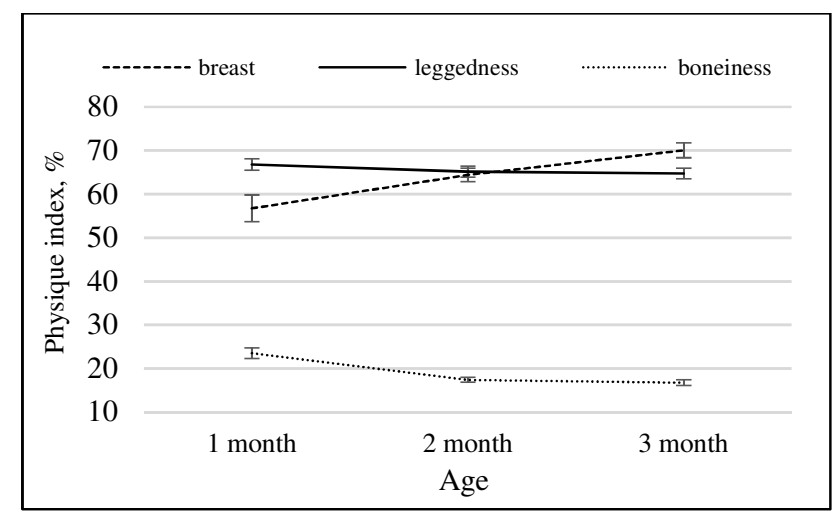

Fig. 5. Physique indices of goats according to the indices of longleggedness, boneiness and breast (average values for all groups).

Our data are generally consistent with the results of studies [16], indicating the absence of a significant effect of the use of probiotics (lactococcus, lactobacillus, yeast) in the diet on the exterior performance of the Saanen breed. At the same time, data are presented [17], where the Osmanabadi kids, who received a probiotic preparation (lactobacillus, streptococcus, yeast) with their diet, exceeded the control peers in chest circumference by $2.77 \%$ and body length by $2.96 \%$.

\section{Conclusion}

The introduction of an experimental probiotic preparation "Plantarum" based on Lactobacillus plantarum, Propiobacterium freudenreihii into the diet of female goats in the Saanen breed type in the second half of pregnancy contributed to an increase in the percentage of preservation of their kids. Feeding the probiotic to goats did not have a significant effect on body measurements and body build indices of goats, however, it had a positive effect on body weight and absolute growth of kids. The maximum positive effect was observed with the introduction of a probiotic preparation into the diet of pregnant goats at a dose of 0.8 $\mathrm{ml} / \mathrm{kg}$ of body weight per day.

\section{Funding}

The results were obtained within the framework of research work commissioned by the Ministry of Agriculture of the Russian Federation at the expense of the federal budget (state task No. 08200243-21-01 of 19.07.2021)

\section{References}

1. S.A. Khatataev, I.E. Pridanova, A.S. Shuvarikov. Sheep, goats, wool business, 4, 33-36 (2015).

2. M.A. Svyazhenina. Izvestiâ Sankt-Peterburgskogo gosudarstvennogo èkonomičeskogo universiteta, 53, 154-159 (2018).

3. L. Zábranský, A. Poborská, G. Malá, B. Gálik, E. Petrášková, N. Kernerová, O. Hanušovský, J. Kučera. Journal of Central European Agriculture, 22, 14-18 (2021). 
4. K. Ekwemalor, E. Asiamah, B. Osei, H. Ismail, M. Worku. Journal of Molecular Biology Research, 7, 8898 (2017).

5. E. Pilyukshina, V. Khaustov, V. Rusanova, A. Popelyaev, E. Mashkina, V. Sarychev. E3S Web of Conferences, 203 (2020).

6. A.I. Afanasyeva, V.A. Sarychev, S.G. Katamanov. Sheep, goats, wool business, 4, 53-55 (2018).

7. M.A Galina, M.A. Ortiz-Rubio, M. Delgado-Pertiñez, L.J. Pineda. Nutritional and foraging ecology of sheep and goats (Zaragoza, 2009).

8. E.M. Utz, A.L. Apás, M.A. Díaz, S.N. González, M.E. Arena. Small Ruminant Research, 161, 24-27 (2018).

9. A.L. Apás, M.E. Arena, S. Colombo, S.N. González. Journal of Dairy Science, 98, 47-54 (2015).

10. Z. Ma, Y. Cheng, S. Wang, J. Ge, H. Shi, J. Kou. Journal of Animal Physiology and Animal Nutrition, 104, 44-55 (2020).

11. I.A. Funk, N.I. Vladimirov, A.P. Kravchenko, R.V. Dorofeev, A.V. Grebenshchikova. IOP Conf. Series: Earth and Environmental Science, 723, 022012 (2021).

12. E.G. Skvortsova, O.V. Filinskaya, E.A. Pivovarova, O.V. Lebedeva, A.M. Lebedev. Izvestia Orenburg State Agrarian University, 83, 325-328 (2020).

13. A.S. Jinturkar, B.V. Gujar, D.S. Chauhan, R.A. Patil. Indian Journal of Animal Research, 43, 49-52 (2009).

14. K.S. Sivadasan, S. Subramannian. Journal of Animal Research, 10, 1063-1065 (2020).

15. Mamta, P. Sharma. Haryana Veterinarian, 47, 39-40 (2008).

16. C. Atasoglu, H.I. Akbag, C. Tolu, G. Das, T. Savas, I.Y. Yurtman. South African Journal of Animal Science, 40, 363-370 (2010).

17. S.A. Kochewad, J.M. Chahande, A.B. Kanduri, D.S. Deshmukh, S.A. Ali, V.M. Patil. Veterinary World, 2, 29-30 (2009). 